\title{
Laser Firing in Silicon Heterojunction Interdigitated Back Contact Architecture for Low Contact Resistance
}

\author{
Siddhartha Garud ${ }^{\mathrm{a}, \mathrm{b}, *}$, Cham Thi Trinh ${ }^{\mathrm{a}}$, Holger Rhein $^{\mathrm{c}}$, Sven Kühnapfel ${ }^{\mathrm{a}, \mathrm{b}}$, Stefan Gall ${ }^{\mathrm{a}, \mathrm{b}}$, Rutger Schlatmann ${ }^{\mathrm{c}}$, Bernd \\ Rech $^{\mathrm{a}}$, Daniel Amkreutz ${ }^{\mathrm{a}}$

\begin{abstract}
${ }^{a}$ Institute for Silicon Photovoltaics, Helmholtz Zentrum Berlin für Materialien und Energie GmbH, 12489 Berlin, Germany
${ }^{b}$ Helmholtz Innovation Lab HySPRINT, Helmholtz Zentrum Berlin für Materialien und Energie GmbH, 12489 Berlin, Germany ${ }^{c}$ PVcomB, Helmholtz Zentrum Berlin für Materialen und Energie GmbH, 12489 Berlin, Germany
\end{abstract}

\begin{abstract}
This work reports a laser firing technique applied to completed silicon heterojunction interdigitated back contact solar cells in order to lower contact resistance. Previously, the implementation of a-Si:H(i) at the electron contact of polycrystalline silicon solar cells on glass substrates led to an increase in series resistance. The cell architecture with the current record efficiency of $14.2 \%$ (with illumination through glass) utilizes only an a-Si:H(n+) layer and $2-2.9 \mathrm{~mA} \mathrm{~cm}^{-2}$ of short circuit current density is lost due to electrical shading under the electron contact [1, [2]. The goal of implementing an a-Si:H(i) layer and laser firing at this contact is to achieve low contact resistance at fired spots while preserving a-Si:H(i) passivation in unfired regions. After the laser firing, $V_{O C}$ was retained, while up to $14 \%$ absolute increase in $F F$ was obtained with a mere $0.2 \mathrm{~mA} \mathrm{~cm}^{-2}$ loss in $J_{S C}$. In the best performing cell, a $72.1 \% F F$ was achieved with a $0.7 \mathrm{~mA} \mathrm{~cm}^{-2}$ loss in $J_{S C}$. Two laser sources were used to first ablate a part of the silver contact metal, and then to laser fire through the $\mathrm{Si}(\mathrm{n}) / \mathrm{a}-\mathrm{Si}: \mathrm{H}(\mathrm{i} / \mathrm{n}+) / \mathrm{ITO} / \mathrm{Ag}$ contact. The optimal laser fluence was found to be $1.1-0.5 \mathrm{~J} \mathrm{~cm}^{-2}(355 \mathrm{~nm}$, picosecond pulse duration) and $4.4-5.2 \mathrm{~J} \mathrm{~cm}^{-2}(532 \mathrm{~nm}$, nanosecond pulse duration), respectively. The upper limit on specific contact resistance in the laser fired spots was calculated to be $38 \pm 20 \mathrm{~m} \Omega \mathrm{cm}^{2}$ as a conservative estimate.
\end{abstract}

Keywords: Laser fired contacts, Passivation, Silicon Heterojunction, Interdigitated back contact, liquid phase crystallized silicon, foreign substrates

\section{Introduction}

The current world record efficiency on silicon wafer solar cells of $26.7 \%$ has been demonstrated on a silicon heterojuction, interdigitated back contact (SHJ-IBC) architecture that utilizes the excellent passivation qualities of hydrogenated, intrinsic amorphous silicon (a-Si:H(i)) 3 . The same architecture has been developed to study the capabilities of solar cells made on thin-film, polycrystalline silicon on glass substrates 4, 5. The growth of high quality, 5-40 $\mu \mathrm{m}$ polycrystalline silicon on foreign substrates is a promising approach to lower energy consumption and material usage in the fabrication of silicon solar cells [6] In this paper, we detail a laser firing approach that can improve contact resistance on fully completed thin-film silicon solar cells. It was developed in order to address a series resistance limitation at the electron collector contact. As an application of laser firing on a silicon heterojuction architecture with n-type bulk, it may be of interest to other groups working on industry-relevant fabrication techniques for IBC or SHJ-IBC architectures [7, 8]. Complementary works on laser firing on IBC cells include n-type

\footnotetext{
* Corresponding author

Email address: siddhartha.garud@helmholtz-berlin.de (Siddhartha Garud)
}

dopant sources such as $\mathrm{POCl}_{3}$, Sb, phosphorous doped silicon carbide $\left(\mathrm{a}-\mathrm{SiC}_{\mathrm{x}}(\mathrm{n})\right)$ or phosphorous spin-on dopants [8, 9, 10, 11.

One method of liquid phase crystallization (LPC), is to locally melt silicon with a line-shaped laser energy source scanning across the substrate. This method creates grain sizes in the centimeter scale in the laser scanning direction and in the millimeter scale in the perpendicular direction. The material quality produced by LPC-Si has so far demonstrated $14.2 \%$ solar cell efficiency and an open-circuit voltage $\left(V_{O C}\right)$ of up to $670 \mathrm{mV}$ with bulk thickness $\leq 15 \mu \mathrm{m}$ and illumination through the glass substrate 2, 5]. Laser crystallization in ambient air and scalable, inkjet-based architectures have also been demonstrated previously using heterojunction hole collectors and a point-contact scheme [11, 12.

In the SHJ-IBC architecture on n-type LPC-Si, charge collection under the electron collector fingers has been a limiting factor until now. Low diffusion length of the minority carriers (holes) in the range of $20-50 \mu \mathrm{m}$ dictates the geometry of the IBC architecture [13. Electron collector widths then need to ideally be between $40-100 \mu \mathrm{m}$ so that sufficient photogenerated holes underneath the fingers can travel to the hole collector before recombination. Implementation of a well passivating a-Si:H(i) layer led to high 
contact resistance and a low fill-factor due to narrow widths $(60-120 \mu \mathrm{m})$ of the contact fingers and surface morphology of LPC-Si. The influence of deposition conditions of the a-Si:H(i) layer itself can also not be excluded. The electron collector was ultimately made with only a-Si:H(n+) passivation and a low contact resistance $\left(60 \pm 10 \mathrm{~m} \Omega \mathrm{cm}^{2}\right.$ as measured on a textured wafer [1). The loss in charge collection due to this choice of contact was quantified using high resolution light beam induced current measurements and was found to be $2 \mathrm{~mA} \mathrm{~cm}^{-2}$ of short-circuit current density $\left(J_{S C}\right)$. Using the same measurements, the effective diffusion length of holes under these fingers was calculated to be $14-19 \mu \mathrm{m}$ [1]. The record $14.2 \%$ efficiency was achieved despite this limitation [5].

To surpass this limitation, a laser firing process was developed which aims to achieve a high fill-factor while still maintaining a-Si:H(i) passivation in unfired regions. A schematic of the cell architecture and the laser firing are shown in Fig,1(a). A top-view schematic of a cell and an optical image of the laser firing are shown in Fig 1(b). The laser firing was performed on top of all electron collector fingers but with non over-lapping spots.

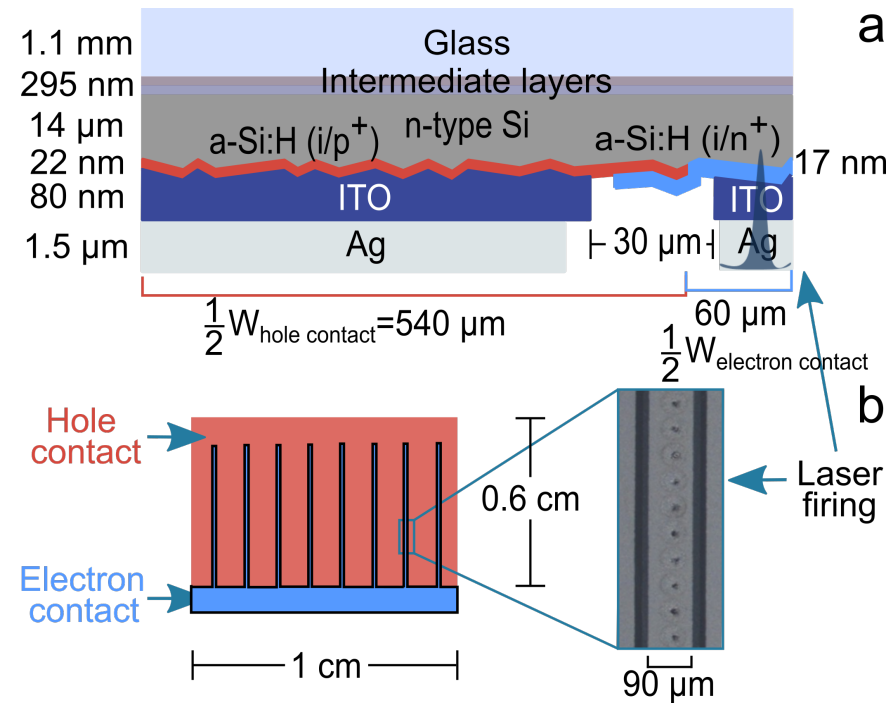

Figure 1: (a) Cross-sectional schematic of a SHJ-IBC unit cell on glass and location of laser firing. (b) Top view schematic of a $1 \mathrm{cmx} 0.6 \mathrm{~cm}$ IBC cell. The magnified image shows the laser firing on an electron collector finger.

\section{Experimental Procedure}

\subsection{Cell fabrication}

Corning Eagle XG $1.1 \mathrm{~mm}$ thick glass substrates are first cleaned in an alkaline solution made from Mucasol in a commercial glass washing machine from Miele. An in-

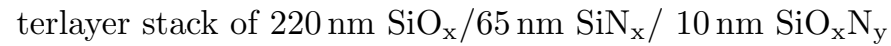
is then deposited via plasma enhanced chemical vapor deposition (PECVD). It has been optimised to provide excellent chemical and electrical passivation, thermal compatibility and adhesion during the crystallization process, anti-reflection and to block the diffusion of dopants from the glass 14. Intrinsic silicon is then evaporated with an electron beam up to a thickness of approximately $15 \mu \mathrm{m}$ at a rate of $600 \mathrm{nms}^{-1}$ and a substrate temperature of approximately $500^{\circ} \mathrm{C}$. A dopant source of $80 \mathrm{~nm}$ thick, phosphorous doped a-Si:H(n+) layer is deposited on top via PECVD. $100 \mathrm{~nm}$ of $\mathrm{SiO}_{\mathrm{x}}$ is also deposited via PECVD to prevent dewetting during the crystallization process. All layers till this step are deposited without a break in vacuum in a Von Ardenne CS400PS integrated CVD/PVD cluster tool. A bulk doping density of $2.5 \pm 0.7 \times 10^{16} \mathrm{~cm}^{-3}$ was used in this work. Where specified, some cells with doping densities of $7.7 \pm 2.7 \times 10^{16} \mathrm{~cm}^{-3}$ were also used.

A line-shaped continuous wave diode laser with a wavelength of $808 \mathrm{~nm}$ and power density $<3.5 \mathrm{~kW} \mathrm{~cm}^{-2}$ is then used to crystallize the deposited micro-crystalline silicon into polycrystalline quality at a scan speed of $3 \mathrm{~mm} \mathrm{~s}^{-1}$, under vacuum conditions. Depending on the laser source, local regions of $0.177-0.3 \mathrm{~mm}$ width irradiated by the moving laser are temporarily liquified which then subsequently cool and recrystallize. Residue stress in the glass substrates is released by rapid thermal annealing at $950{ }^{\circ} \mathrm{C}$. This step is followed by the removal of the $100 \mathrm{~nm} \mathrm{SiO}_{\mathrm{x}}$ capping layer, hydrogen plasma treatement and $\mathrm{KOH}$ based texturing as detailed in 5 .

Two PECVD steps and three photolithography steps are used to create a SHJ-IBC architecture on $1 \mathrm{~cm} \times 0.6 \mathrm{~cm}$ cells on $5 \mathrm{~cm} \times 5 \mathrm{~cm}$ substrates. The hole collector contact consists of $7 \mathrm{~nm}$ a-Si:H(i) and $15 \mathrm{~nm}$ a-Si:H(p+) layers (expected thickness on textured silicon) contacted using $80 \mathrm{~nm}$ sputtered indium tin oxide (ITO) and $1.5 \mu \mathrm{m}$ sputtered silver. Its width is fixed at $1080 \mu \mathrm{m}$. Previously, the electron collector contact comprised of only $10 \mathrm{~nm}$ a-Si:H(n+) followed by ITO and silver. Cells with such a contact are used as references in this work. On test cells, $4 \mathrm{~nm}$ and $7 \mathrm{~nm}$ a-Si:H(i) layers underneath $15 \mathrm{~nm}$ a-Si:H(n+) were used. The thickness of the a-Si:H(n+) layers was increased from $10 \mathrm{~nm}$ to $15 \mathrm{~nm}$ to account for different growth conditions on a-Si:H(i) as compared to polycrystalline silicon. Three widths of the electron contact are used, namely, $60 \mu \mathrm{m}$, $90 \mathrm{\mu m}$ and $120 \mathrm{\mu m}$. The metal widths on these fingers are $30 \mu \mathrm{m}, 60 \mu \mathrm{m}$ and $90 \mu \mathrm{m}$ respectively due to under-etching and isolation of contacts.

The photolithography steps used a Microchemicals AZ 4533 photoresist and MA6 SÜSS MicroTec mask aligner and standard RCA cleaning steps. The a-Si:H(i/p+) layers were etched using an aqueous solution consisting of hydrofluoric acid $(\mathrm{HF})$, nitric acid $\left(\mathrm{HNO}_{3}\right)$, and phosphoric acid $\left(\mathrm{H}_{3} \mathrm{PO}_{4}\right)$. Tetramethylammonium (TMAH) was used as a selective etchant for a-Si:H(i/n+). ITO was etched with $20 \%$ hydrochloric acid $(\mathrm{HCl})$ and silver with a diluted solution of ammonia $\left(\mathrm{NH}_{4} \mathrm{OH}\right)$ and hydrogen peroxide $\left(\mathrm{H}_{2} \mathrm{O}_{2}\right)$. Finally, cells were annealed at $180^{\circ} \mathrm{C}$ for $20 \mathrm{~min}$ to reverse damages incurred in the ITO sputtering step. More details can be found in [5]. Fig 1(a) shows a cross-section of the architecture. 


\subsection{Two-step laser firing process for completed solar cells}

Long laser pulse widths in the nanosecond or microsecond regime are most suitable for melting silicon while avoiding ablation [15. The only available wavelength with nanosecond pulse widths in our setup was $532 \mathrm{~nm}$. At this wavelength, the reflectivity of the deposited silver contact metal was measured to be $89.7 \%$ and the laser could not have any effect on the $1.5 \mathrm{\mu m}$ thick silver. The reflectivity of the deposited silver at $355 \mathrm{~nm}$ is $51 \%$ and hence, a picosecond pulse duration, $355 \mathrm{~nm}$ laser was first used to partially ablate the silver. This also reduces the reflectivity of the silver in the process, and hence the $532 \mathrm{~nm}$ laser energy is better absorbed when targeted at the same spots. Both laser sources were operated at $50 \mathrm{kHz}$, and the number of pulses was varied in order to deliver more energy to a spot while avoiding ablation by using a low laser fluence in each pulse.

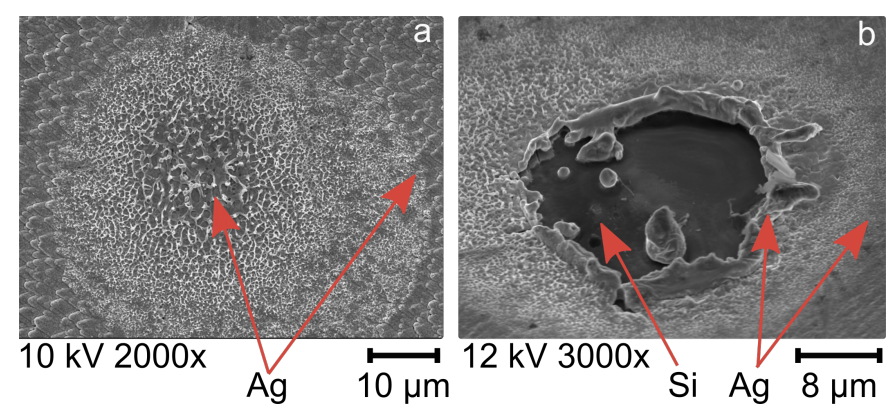

Figure 2: (a) Top view SEM image after the contact metal ablation step using a picosecond pulse duration $355 \mathrm{~nm}$ laser with 12 pulses each with a fluence of $1.1 \mathrm{~J} \mathrm{~cm}^{-2}$. (b) SEM image after the subsequent nanosecond pulse duration $532 \mathrm{~nm}$ laser firing with 160 pulses each with a fluence of $5.2 \mathrm{~J} \mathrm{~cm}^{-2}$. The silicon bulk material visible in the middle was observed to have melted and recrystallized.

The first step uses a $355 \mathrm{~nm}$, picosecond pulse-duration, neodymium-doped, yttrium aluminum garnet (Nd:YAG) laser with a fluence around $1.1 \mathrm{~J} \mathrm{~cm}^{-2}$. The number of pulses was varied from 6 to 12 and 12 was found to give an optimal level of silver ablation (Fig,2(a)) to ensure uniformity in the succeeding laser firing step. The second step uses a neodymium-doped yttrium orthovanadate $\left(\mathrm{Nd}: \mathrm{YVO}_{4}\right)$ laser with a wavelength of $532 \mathrm{~nm}, 16 \mathrm{~ns}$ pulseduration, a 'top-hat' intensity profile and $4.4-6 \mathrm{~J} \mathrm{~cm}^{-2}$ fluence. The number of pulses was varied from 160 to 1010. An optimal energy density window was found to be $4.4-5.2 \mathrm{~J} \mathrm{~cm}^{-2}$ with 160 pulses to avoid ablation of the bulk silicon material (Fig $2(\mathrm{~b})$ ). The temperatures required for melting silver $\left(962^{\circ} \mathrm{C}\right)$ and silicon $\left(1414^{\circ} \mathrm{C}\right)$ are easily achieved with the laser fluences and multiple firing of the nanosecond laser. Fig 2(b) shows melted and solidified bulk silicon in the middle and silver along the edges of the fired contact.

The impact diameter of the picosecond laser was seen to be $50 \mu \mathrm{m}$ at $1.1 \mathrm{~J} \mathrm{~cm}^{-2}$ and $33 \mu \mathrm{m}$ at $0.5 \mathrm{~J} \mathrm{~cm}^{-2}$. The laser firing was done with a spacing of $10 \mu \mathrm{m}$ between fired regions, with the goal of achieving low contact resistance at the fired spots while preserving passivation in unfired regions. The nanosecond laser was seen to affect a diameter of $33 \mu \mathrm{m}$. The metal edges of the contact fingers were used as alignment markers for the picosecond laser. The nanosecond laser was aligned to the same markers in the vertical direction and the picosecond laser fired spots in the horizontal direction. This enabled excellent alignment even over the high aspect ratio of the fingers $(5 \mathrm{~mm}: 90 \mu \mathrm{m}$ and $(5 \mathrm{~mm}: 60 \mu \mathrm{m})$. The laser sources and XYZ stage are from Rofin laser.

\subsection{Characterization}

Current-voltage (I-V) curves were obtained using a AAA-rated, AM1.5G spectrum, dual source, Wacom WXS156S-L2 solar simulator. Doping concentration was calculated from sheet resistances obtained from four point probe measurements. Scanning electron microscopy (SEM) and energy-dispersive X-ray spectroscopy (EDX) were conducted on a HITACHI S-4100 system.

\section{Results and discussions}

\subsection{Implementation of a-Si:H(i) layer at the electron con- tact}

Around $2 \mathrm{~mA} \mathrm{~cm}^{-2} J_{S C}$ is lost under the electron contact fingers with an a-Si:H(n+)/ITO/Ag contact due to surface recombination 1]. Recent attempts to include $4 \mathrm{~nm}$ and $7 \mathrm{~nm}$ a-Si:H(i) layers were successful in recovering some of this lost current and are shown in Fig, 3 , wherein the average $J_{S C}$ increased by $1.1 \mathrm{~mA} \mathrm{~cm}^{-2}$. The variation in $J_{S C}$ among the plotted cells, can be attributed to three main aspects:

1. Fabrication of three different electron collector finger thicknesses, namely $60 \mu \mathrm{m}, 90 \mu \mathrm{m}$ and $120 \mu \mathrm{m}$ (plotted together here to include maximum data points)

2. Presence of different quantities of grain boundaries in each cell

3. Fluctuations in doping density

\subsection{Changes in electrical parameters with laser firing}

Due to the implementation of a-Si:H(i) at the electron contact, fill-factors were limited to $\leq 62.4 \%$. An example cell is plotted in Fig, 4 (labelled 'Initial'). To circumvent this trade-off, laser firing was attempted on limited areas of the electron contact on completed solar cells. It led to a remarkable improvement in fill-factor on all 15 experimented cells (Fig, 4 and Fig,5(a)). Fill-factor improved by $8.1 \%$ (absolute) on an average, which caused an average $1.2 \%$ absolute increase in cell efficiency (Fig,5(b)). Most of the improvement came from the second, nanosecond laser firing step. This is because the first, picosecond laser firing step is only designed to partially ablate the silver contact metal. The second, nanosecond laser firing step is only then able to melt/ablate $\mathrm{Ag}$, ITO, a-Si:H(i/n+) and bulk Si, resulting in a low resistance contact spot. It is worth noting 


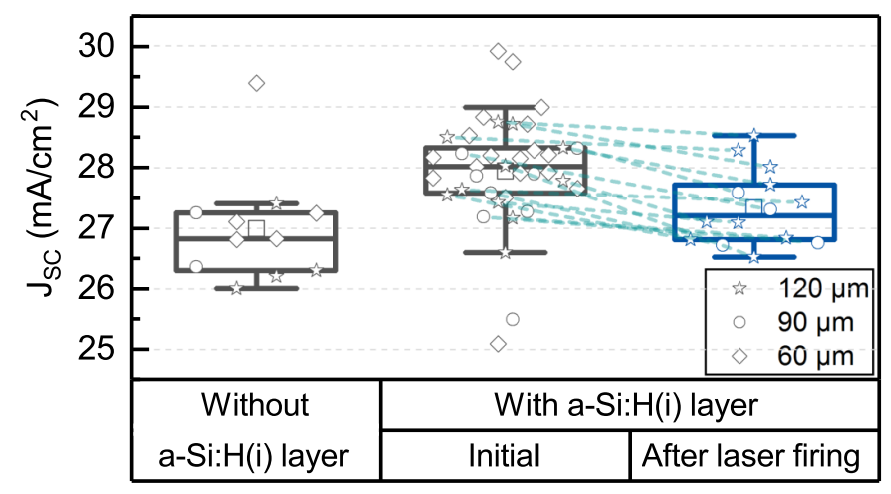

Figure 3: A comparison of short-circuit current density $\left(J_{S C}\right)$ of cells which were processed together at each step. The cells with an a-Si:H(i) passivation layer for the electron collection statistically show an increased charge collection. Different electron contact finger widths are shown with different symbol shapes. The dotted lines connect the data points of individual cells to show the effect of laser firing on $J_{S C}$.

that the $V_{O C}$ was retained in each case (Fig $5(\mathrm{c})$ ) while $J_{S C}$ reduced by $0.2 \mathrm{~mA} \mathrm{~cm}^{-2}$ to $1.5 \mathrm{~mA} \mathrm{~cm}^{-2}$ depending on the laser alignment and firing energy used (Fig $5(\mathrm{~d}))$. The reduction in $J_{S C}$ can be assumed to be arising from a loss of passivation in the fired regions. The series resistance was calculated by the comparison of illuminated and dark J-V curves (Fig 5(e)) 16. The shunt resistance was calculated from the slope of the $\mathrm{J}-\mathrm{V}$ curve, averaged from $-1 \mathrm{~V}$ to $0 \mathrm{~V}$ (Fig [5(f)) [17]. Fig, 3 shows the over-all improvement in charge collection with this approach. A limited amount of $J_{S C}$ is lost in the laser firing process, but there is still an over-all gain in comparison to the previous approach of merely a-Si:H(n+) passivation. In the best cases, only $0.2 \mathrm{~mA} \mathrm{~cm}^{-2}$ was lost for a $14 \%$ absolute gain in fill-factor which demonstrates the effectiveness of this approach. The maximum achieved fill-factor with this trade-off was $72.1 \%$ resulting in a cell efficiency of $11.8 \%$ (without the use of an anti-reflection foil) (Fig 4). One reason for the variation in the $J_{S C}$ loss can be the imperfect alignment in the metal ablation step in some cells. It is this step which affects the largest passivation area and therefore precise centering of the firing on the metal fingers is crucial.

\subsection{Laser firing on cells with a-Si:H(n+)/ITO/Ag contact}

The same laser firing was also attempted on cells with a-Si:H(n+)/ITO/Ag contacts to see if fill-factor on cells could be improved. These trials were performed on four cells from the same batch and doping density as the a$\mathrm{Si}: \mathrm{H}(\mathrm{i})$ layer passivated cells, and cells from another batch with higher doping $\left(7.7 \pm 2.7 \times 10^{16} \mathrm{~cm}^{-3}\right)$. Fig 5 (a) shows that fill-factor is generally higher due to a lower electron contact resistance, with a maximum of $72.6 \%$. An absolute increase in FF between only $0.2 \%$ to $0.9 \%$ was observed with the laser firing. This suggests that contact resistance cannot be improved significantly with laser firing on a$\mathrm{Si}: \mathrm{H}(\mathrm{n}+) / \mathrm{ITO} / \mathrm{Ag}$ contacts, at least with the density of 83 spots on $5 \mathrm{~mm}$ long fingers. The a-Si:H(n+) layer had an

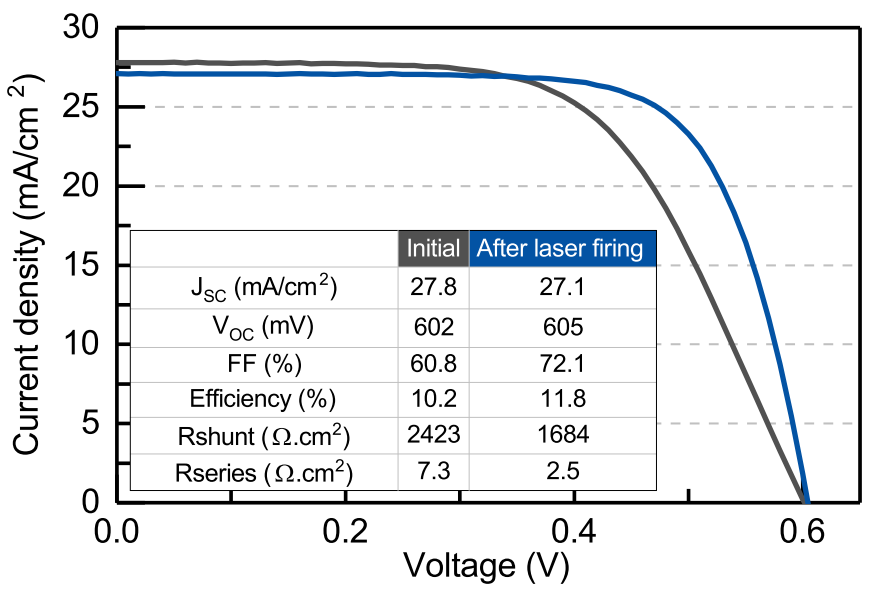

Figure 4: J-V curve of the best result achieved in these experiments before and after laser firing. $V_{O C}$ was retained, while a $0.7 \mathrm{~mA} \mathrm{~cm}^{-2}$ reduction in $J_{S C}$ was traded-off to gain $11.3 \%$ absolute in $F F$. Electron contact finger thickness in this cell was $120 \mu \mathrm{m}$ and bulk doping density was $2.8 \pm 0.4 \times 10^{16} \mathrm{~cm}^{-3}$. The picosecond laser was used to irradiate every spot with 12 pulses each with a fluence of $1.1 \mathrm{~J} \mathrm{~cm}^{-2}$. The subsequent nanosecond laser was used to irradiate the same spots with 160 pulses each with a fluence of $5.2 \mathrm{~J} \mathrm{~cm}^{-2}$.

expected thickness of $10 \mathrm{~nm}$ in these cells, and $15 \mathrm{~nm}$ in the cells with a-Si:H(i/n+) contact. Further investigations are required to know if the additional thickness has a doping effect in the laser fired regions. $J_{S C}$ showed little or no change within the resolution of measurement, which is in agreement with previous studies based on light beam induced current measurements [1, 2. They prove that the electron contact without a-Si:H(i) has low charge collection (a phenomenon called electrical shading).

Fig.5 shows that in the best cases, fill-factor in cells with a-Si:H(i/n+)/ITO/Ag and laser firing at the electron contact is comparable to fill-factor in cells without a-Si:H(i). There is a gain in $J_{S C}$ with the new approach as evidenced in Fig.5(d) and Fig.3 (which compares only cells at the same doping density). However, the best cell efficiency is still shown by a cell without a-Si:H(i) due to higher $V_{O C}$. This is due to the following reasons:

1. Cells with higher doping density show a higher average $V_{O C}$. This effect has also been specifically investigated for LPC-Si cells [18, 19]. In Fig 5, cells at the same doping level of $2.5 \pm 0.7 \times 10^{16} \mathrm{~cm}^{-3}$, exhibit a higher $V_{O C}$ with a-Si:H(i) present at the electron contact than without. This is unchanged by the laser firing. Doping density may need to be optimised to achieve a $V_{O C} \geq 650 \mathrm{mV}$

2. Even with the same laser crystallization parameters, there is a statistical variation in the amount of grain boundaries that can be present in a cell. This has a significant impact on $V_{O C}, J_{S C}$ and $F F$ [1, 2, Passivation quality at both electron and hole contacts are also impacted by surface morphology on polycrystalline silicon.

Therefore, due to the increase in charge collection from 


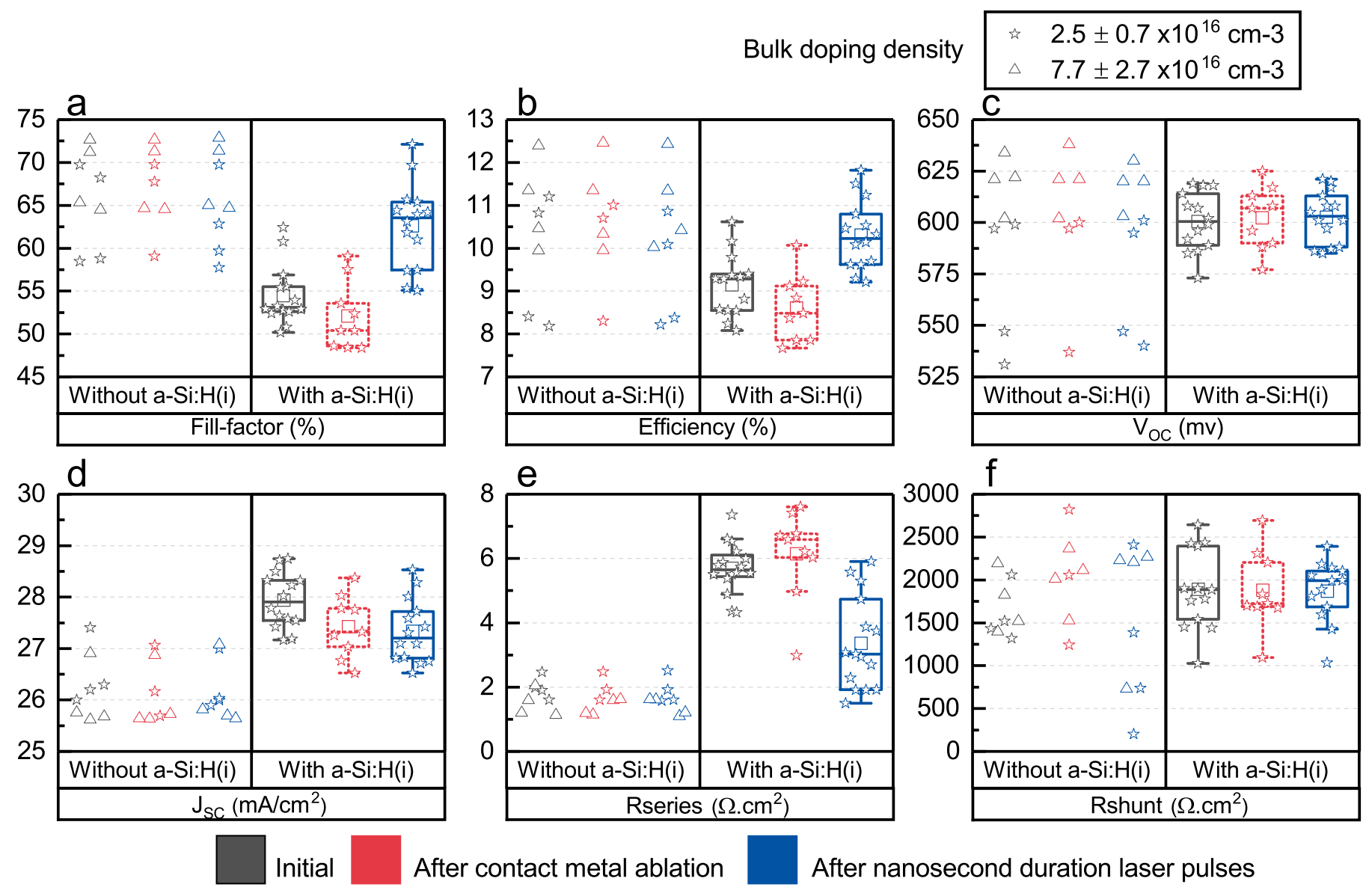

Figure 5: Electrical parameters show that fill-factor $(F F)$ and efficiency improved with laser firing on a-Si:H(i/n+)/ITO/Ag contacts. The same firing density showed little or no improvements on a-Si:H(n+)/ITO/Ag contacts (i.e without a-Si:H(i)). The cells with a-Si:H(i/n+)/ITO/Ag were all processed together and with the same bulk doping and hence, box plots are shown for their statistical distribution. The lines of the boxes mark the $25^{\text {th }}, 50^{\text {th }}$ and $75^{\text {th }}$ percentiles. The means are marked by empty squares. The box plots representing the contact metal ablation step are shown in dotted lines as this is an intermediate step and not all cells were subjected to this measurement.

the electron contact regions (Fig 3 , it is expected that optimization of doping density and number of grain boundaries can help exceed the current record efficiency of $14.2 \%$ if a comparable fill-factor can be achieved from the laser firing.

\subsection{Estimation of specific contact resistance}

The improvement in fill-factor came from the reduction of contact resistance at the a-Si:H(i/n+)/ITO/Ag contact. Therefore, the series resistance values derived from measurements before and after laser firing were used to calculate the contact resistance of the laser fired spots.

All components of series resistance can be written as follows (in $\Omega \mathrm{cm}^{2}$ with respect to cell area):

$$
R_{\mathrm{series}}=R_{\mathrm{bulk}}+R_{\mathrm{hc}}+R_{\mathrm{metal}}+R_{\mathrm{ec}}=R_{\mathrm{rest}}+R_{\mathrm{ec}}
$$

Here $\mathrm{R}_{\text {bulk }}, \mathrm{R}_{\mathrm{hc}}, \mathrm{R}_{\mathrm{ec}}$ and $\mathrm{R}_{\text {metal }}$ represent the contributions of the bulk, hole contact, electron contact and metal fingers (of both contacts) to the series resistance, respectively. 'R $\mathrm{R}_{\text {rest }}$ ' groups together the components which are unaffected by the laser firing (namely, resistance in bulk, hole collector and metal fingers).
Let ' $R_{\mathrm{ec}}$ ' represent the resistance at the a$\mathrm{Si}: \mathrm{H}(\mathrm{i} / \mathrm{n}+) / \mathrm{ITO} / \mathrm{Ag}$ contact before laser firing. After laser firing, we use ' $R_{\text {ec_LF }}$ ' to represent the resistance in the fired spots and 'R $\mathrm{ec}_{\text {NNLF' }}$ for the unfired regions. Then a simple circuit diagram as drawn in Fig 6 can be used.

The change in the total series resistance can be written as follows:

$$
\Delta R_{\text {series }}=\left(R_{\text {ec }}+R_{\text {rest }}\right)-\left(R_{\text {ec_LF }} \| R_{\text {ec_NLF }}+R_{\text {rest }}\right)
$$

Equation 2 can be re-written to obtain the specific contact resistance of the laser fired spots (in $\Omega \mathrm{cm}^{2}$ with respect to laser fired area) as:

$$
\begin{gathered}
R_{\text {ec_LF }}=\frac{R_{\text {ec_NLF }} *\left(R_{\mathrm{ec}}-\Delta R_{\text {series }}\right)}{\Delta R_{\text {series }}+R_{\text {ec_NLF }}-R_{\text {ec }}} \\
\rho_{\text {contact_LF }}\left(\Omega \mathrm{cm}^{2}\right)=R_{\text {ec_LF }} * \frac{A_{\text {fired }}}{A_{\text {cell }}}
\end{gathered}
$$

Therefore, a conservative estimate of the contact resistance at the a-Si:H(i/n+)/ITO/Ag contact (i.e, $\mathrm{R}_{\mathrm{ec}}$ and $\mathrm{R}_{\text {ec_NLF }}$ which only differ in area as shown in equation 4 . can give a corresponding conservative estimate of the specific contact resistance in the laser fired spots ( $\left.\rho_{\text {contact_LF }}\right)$. 


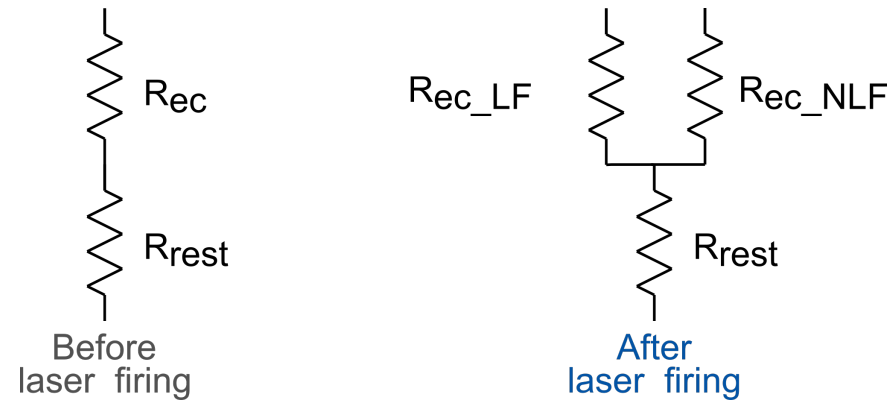

Figure 6: Circuit model used to calculate the contact resistance of the laser fired spots. The resistances (in $\Omega \mathrm{cm}^{2}$ ) are represented as: ' $\mathrm{R}_{\mathrm{ec}}$ ' at the $\mathrm{Si}(\mathrm{n}) / \mathrm{a}-\mathrm{Si}: \mathrm{H}(\mathrm{i} / \mathrm{n}+) / \mathrm{ITO} / \mathrm{Ag}$ contact before laser firing; ' $R_{\text {ec L LF' }}$ in the laser fired spots and ' $R_{\text {ec } N L F}$ ' in the unfired regions. ' $R_{\text {rest }}$ ' are the other components of the total series resistance.

$\mathrm{A}_{\text {fired }}$ is the total area of the fired spots. They were taken to be $33 \mu \mathrm{m}$ in diameter which is the impact diameter for the nanosecond laser, since it was this laser that was seen to cause the increases in fill-factor (Fig 5 ). Each of the 8 contact fingers had 83 such laser fired spots. The different contact areas in cells are as listed in the appendix (equation 5).

In order to calculate an upper estimate of ' $R_{\mathrm{ec}}$ '

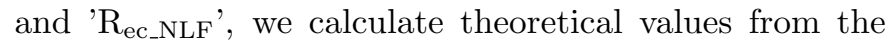
other contributing parts and subtract them from the total series resistance. The specific contact resistance of the a-Si:H(i/p+)/ITO/Ag contact was taken to be $335 \pm 70 \mathrm{~m} \Omega \mathrm{cm}^{2}$ as measured with TLM structures on textured wafers [1. The contribution of the bulk and metal fingers was calculated as proposed by Yang et al. for IBC cells 20]. It uses an integration of the power loss from the tips of contact fingers to the busbars to get an effective series resistance in an IBC architecture.

$$
\begin{array}{r}
R_{\mathrm{ec}}=R_{\text {series }}-\left(R_{\mathrm{bulk}}+R_{\mathrm{hc}}+R_{\text {metal }}\right) \\
R_{\mathrm{ec \_ NLF}}=R_{\mathrm{ec}} * \frac{A_{\text {electron contact }}}{A_{\text {non_fired_regions }}}
\end{array}
$$

The observed total cell series resistances in this work (Fig $5(\mathrm{e})$ ) and in previous experiments by Trinh et al., are higher than theoretically expected. For example, they are in the range of $1-3.5 \Omega \mathrm{cm}^{2}$ for cells with electron contacts of a-Si:H(n+)/ITO/Ag and widths of $120 \mu \mathrm{m}$ and $90 \mu \mathrm{m}$ [5]. This suggests that the contributions from one or all components (electron contact, hole contact and bulk) are higher than those calculated theoretically due to the following reasons [5]:

1. Higher contact resistance on randomly textured LPCSi than that measured on uniformly textured wafers

2. Local fluctuations in doping density in the bulk

However, by assuming the contribution of the hole contact on LPC-Si to be the same as measured on Si wafer, that of the bulk resistance from an average value of doping density, and attributing all the remaining series resistance to the electron contact, we obtain a conservative, upper limit on the contribution of the a-Si:H(i/n+)/ITO/Ag contact. These values are shown in Table 1. From these values, we get an upper limit for the specific contact resistance of the fired spots using equation 3 .

The specific contact resistance of the laser fired spots was observed to be in the range of 13.6 to $72.7 \mathrm{~m} \Omega \mathrm{cm}^{2}$ and can be expressed with an average value of $38 \pm 20 \mathrm{~m} \Omega \mathrm{cm}^{2}$. These values were calculated from 11 out of the 15 tested cells, excluding 4 outlier cells where imperfect laser alignment may have reduced the total fired area assumed in these calculations. The real value of specific contact resistance is likely lower than this one since it was calculated with a conservative, upper limit estimate.

In comparison, the a-Si:H(n+)/ITO/Ag contact (i.e without a-Si:H(i)) was measured to have specific contact resistance of $60 \pm 10 \mathrm{~m} \Omega \mathrm{cm}^{2}$ on textured wafers. When this method of calculation was used on LPC-Si cells plotted in Fig 5 with such a contact, the specific contact resistance in the laser fired spots in these cells was estimated to be $45 \pm 12 \mathrm{~m} \Omega \mathrm{cm}^{2}$, which is in agreement with the range of the results in Table 1 .

\subsection{Physical effects of the laser firing}

The SEM image in Fig 2(a) shows the effect of the picosecond laser firing. Only a thin layer of silver is left on top of the a-Si:H(i/n+)/ITO stack. Fig 2(b) shows the effect of the subsequent nanosecond laser firing. The silicon bulk melts and recrystallizes in the affected region. Silver, Indium, Tungsten and amorphous silicon have either been ablated or diffused into the molten silicon. When the mix solidifies and re-crystallizes, we hypothesize that a silver silicide is formed which creates a low resistance contact with the surrounding silver. It is also possible that the melted and solidified silicon is more conductive than the rest due to dopant segregation and structural changes [21]).

Silver can introduce energy levels deep in the silicon bandgap, the most prominent ones being an acceptor-type level at $0.54 \mathrm{eV}$ below the conduction band and a donortype level at $0.34 \mathrm{eV}$ above the valence band [22]. However, at most $1 \%$ of dissolved silver is electrically active in Silicon [23]. Indium can be a p-type dopant, albeit with high ionization energies. Oxygen and especially tin can contribute to deep energy states in the Silicon bandgap [24. However, since no detrimental effect was observed in this experiments, it can be presumed that either a majority of these elements were ablated away, or that the amount of elements dissolved and electrical active are insufficient to affect the $V_{O C}$. In SEM-EDX measurements, the presence of both silver and silicon was detected in some areas of the laser fired contact, especially along the borders (Fig 7 and Fig, 8 in appendix). The presence of oxygen seemed to be higher in the fired spots, but no traces of tin or indium were to be seen within the resolution of the EDX detector. 


\begin{tabular}{|c|c|c|c|c|c|c|c|}
\hline \multirow{3}{*}{$\begin{array}{c}\text { Bulk doping } \\
\text { and electron } \\
\text { contact width }\end{array}$} & \multirow{3}{*}{$\begin{array}{l}\text { Total } R_{\text {series }} \\
\text { Before } \\
\text { Laser firing }\end{array}$} & \multicolumn{3}{|c|}{ Contributions assumed ideal } & \multirow{2}{*}{\multicolumn{2}{|c|}{$\begin{array}{l}\text { Remaining } \mathrm{R}_{\text {series }} \text { attributed } \\
\text { to electron contact }\end{array}$}} & \multirow{3}{*}{$\begin{array}{c}\text { Maximum specific } \\
\text { contact resistance } \\
\text { Laser fired spots }\end{array}$} \\
\hline & & Bulk & Hole & Contact & & & \\
\hline & & & contact & metal & Before laser firing & After laser firing & \\
\hline & $\mathrm{R}_{\text {series }}$ & $\mathrm{R}_{\text {bulk }}$ & $\mathrm{R}_{\mathrm{hc}}$ & $\mathrm{R}_{\text {metal }}$ & $\mathrm{R}_{\mathrm{ec}}$ & $\mathrm{R}_{\mathrm{ec} \_ \text {LF }} \| R_{\mathrm{ec} \_ \text {NLF }}$ & $\rho_{\text {contact_LF }}$ \\
\hline $\mathrm{cm}^{-3} ; \mu \mathrm{m}$ & $\Omega \mathrm{cm}^{2}$ & $\Omega \mathrm{cm}^{2}$ & $\Omega \mathrm{cm}^{2}$ & $\Omega \mathrm{cm}^{2}$ & $\Omega \mathrm{cm}^{2}$ & $\Omega \mathrm{cm}^{2}$ & $\mathrm{~m} \Omega \mathrm{cm}^{2}$ \\
\hline $2.4 \pm 0.5 * 10^{16} ; 120$ & 4.4 & 0.2 & 0.4 & 0.014 & 3.8 & 1.3 & 17.0 \\
\hline $2.4 \pm 0.8 * 10^{16} ; 120$ & 6.5 & 0.2 & 0.4 & 0.014 & 5.9 & 3.3 & 72.7 \\
\hline $2.4 \pm 0.8 * 10^{16} ; 120$ & 6.3 & 0.2 & 0.4 & 0.014 & 5.7 & 2.3 & 40.8 \\
\hline $2.5 \pm 0.5 * 10^{16} ; 120$ & 5.4 & 0.2 & 0.4 & 0.014 & 4.8 & 1.3 & 19.9 \\
\hline $2.5 \pm 0.5 * 10^{16} ; 120$ & 7.4 & 0.2 & 0.4 & 0.014 & 6.8 & 2.1 & 32.8 \\
\hline $2.8 \pm 4.5 * 10^{16} ; 120$ & 4.9 & 0.2 & 0.4 & 0.014 & 4.3 & 1.3 & 21.0 \\
\hline $2.8 \pm 4.5 * 10^{16} ; 120$ & 4.3 & 0.2 & 0.4 & 0.014 & 3.7 & 0.9 & 13.6 \\
\hline $2.4 \pm 0.5 * 10^{16} ; 90$ & 5.9 & 0.2 & 0.4 & 0.019 & 5.3 & 1.7 & 26.1 \\
\hline $2.8 \pm 4.5 * 10^{16} ; 90$ & 5.5 & 0.2 & 0.4 & 0.019 & 4.2 & 1.7 & 63.1 \\
\hline $2.5 \pm 0.5 * 10^{16} ; 90$ & 7.4 & 0.2 & 0.4 & 0.019 & 6.8 & 3.1 & 59.4 \\
\hline $2.5 \pm 0.5 * 10^{16} ; 90$ & 5.5 & 0.2 & 0.4 & 0.019 & 4.9 & 2.5 & 49.5 \\
\hline
\end{tabular}

Table 1: Break-up of total series resistance into its components. The contributions from the bulk, hole contact and metal were assumed to be ideal in order to get an upper estimate on the contact resistance at the a-Si:H(i/n+)/ITO/Ag contact. Using the change in series resistance observed after laser firing, a conservative estimate on the specific contact resistance in the laser fired spots was made as listed here.

\section{Conclusion and Outlook}

This paper showcases a laser firing method to lower contact resistance on completed SHJ-IBC cells made on thin-film, polycrystalline silicon with $1.5 \mu \mathrm{m}$ thick Ag contact metal as the top-most layer. A key advantage of this method of laser firing on the electron collector fingers in LPC-Si cells, is that $V_{O C}$ is retained in each case. Up to $14 \%$ absolute increase in fill-factor was obtained with a $0.2 \mathrm{~mA} \mathrm{~cm}^{-2}$ loss in $J_{S C}$. In the best performing cell with $11.8 \%$ efficiency (without anti-reflection foil), a $72.1 \%$ fillfactor was achieved with a $0.7 \mathrm{~mA} \mathrm{~cm}^{-2}$ loss in $J_{S C}$. This trade-off allows the passivation of the $90-120 \mu \mathrm{m}$ wide electron contact fingers which was not previously possible without a significant degradation in fill-factor. This is an important step forward for polycrystalline silicon on glass, because in the cell architecture with the current record efficiency of $14.2 \%, 2-2.9 \mathrm{~mA} \mathrm{~cm}^{-2}$ is lost due to electrical shading under the electron contact [1, [2]. Therefore, the work presented here serves as a proof-of concept for reducing this loss and achieving higher efficiency. To achieve this, the same results have to be replicated with optimal bulk doping and laser crystallization parameters which reduce grain boundaries/dislocations. Both can lead to a higher $V_{O C}$ and $J_{S C}$ as demonstrated in several works before [1, 15, 19. The loss in $J_{S C}$ due to laser firing is also a factor of the laser alignment and the impact diameter in the metal ablation step. Future efforts will involve improved alignment and a reduction in the impact diameter from $50 \mu \mathrm{m}$ to $33 \mu \mathrm{m}$ by reducing the laser fluence from $1.1 \mathrm{~J} \mathrm{~cm}^{-2}$ to $0.5 \mathrm{~J} \mathrm{~cm}^{-2}$ and compensating by an increased number of laser pulses. The optimal laser energy window for the other, nanosecond laser firing was observed to be $4.4-5.2 \mathrm{~J} \mathrm{~cm}^{-2}$, with 160 pulses.

The specific contact resistance in the laser fired spots was calculated to be $38 \pm 20 \mathrm{~m} \Omega \mathrm{cm}^{2}$. The actual value is expected to be lower than this since conservative calcu- lations were made to find an upper limit on the specific contact resistance. Laser firing through silver, ITO and amorphous silicon layers may also be of interest for other laser based cell fabrication approaches, especially if the laser fired contacts are locally doped to repeal carriers of the opposite polarity 77, 8. Further investigations are need to know if a-Si:H(n+) or a-Si:H(p+) can provide local doping.

\section{Acknowledgements}

Financial support from the European Regional Development fund and the state government of North RhineWestphalia in the framework of the Up-LLPC Project (Grant EFRE-0800580 and EU-1-2-037C) is gratefully acknowledged. This work is also financially supported by the Helmholtz Innovation Lab HySPRINT. The authors would like to thank Martin Muske, Stefanie Severin, Martina Trahms and Larissa Apel for help with solar cell preparation, Christof Schultz for supervising the Rofin laser system and Carola Klimm for the SEM images.

\section{References}

[1] P. Sonntag, N. Preissler, M. Bokalič, M. Trahms, J. Haschke, R. Schlatmann, M. Topič, B. Rech, D. Amkreutz, Silicon solar cells on glass with power conversion efficiency above $13 \%$ at thickness below 15 micrometer, Scientific reports 7 (1) (2017) 873.

[2] C. T. Trinh, M. Bokalič, N. Preissler, M. Trahms, D. Abou-Ras, R. Schlatmann, D. Amkreutz, M. Topič, Assessment of bulk and interface quality for liquid phase crystallized silicon on glass, IEEE Journal of Photovoltaics 9 (2) (2019) 364-373.

[3] M. A. Green, E. D. Dunlop, D. H. Levi, J. Hohl-Ebinger, M. Yoshita, A. W. Ho-Baillie, Solar cell efficiency tables (version 54), Progress in Photovoltaics: Research and Applications 27 (7) (2019) 565-575.

[4] P. Sonntag, J. Haschke, S. Kühnapfel, T. Frijnts, D. Amkreutz, B. Rech, Interdigitated back-contact heterojunction solar cell concept for liquid phase crystallized thin-film silicon on glass, 
Progress in Photovoltaics: Research and Applications 24 (5) (2016) 716-724

[5] C. T. Trinh, N. Preissler, P. Sonntag, M. Muske, K. Jäger M. Trahms, R. Schlatmann, B. Rech, D. Amkreutz, Potential of interdigitated back-contact silicon heterojunction solar cells for liquid phase crystallized silicon on glass with efficiency above 14\%, Solar Energy Materials and Solar Cells 174 (2018) 187-195.

[6] J. Haschke, D. Amkreutz, B. Rech, Liquid phase crystallized silicon on glass: Technology, material quality and back contacted heterojunction solar cells, Japanese Journal of Applied Physics 55 (4S) (2016) 04EA04.

[7] U. Das, C. Thompson, U. Nsofor, Z. Sun, M. C. Gupta, S. Hegedus, Effect of dielectric layers on laser-fired-contact performance in a-si/csi heterojunction solar cells, in: 2018 IEEE 7 th World Conference on Photovoltaic Energy Conversion (WCPEC)(A Joint Conference of 45th IEEE PVSC, 28th PVSEC \& 34th EU PVSEC), IEEE, 2018, pp. 2114-2117.

[8] M. Dahlinger, K. Carstens, E. Hoffmann, R. Zapf-Gottwick, J. H. Werner, $23.2 \%$ laser processed back contact solar cell: fabrication, characterization and modeling, Progress in Photovoltaics: Research and Applications 25 (2) (2017) 192-200.

[9] J. He, S. Hegedus, U. Das, Z. Shu, M. Bennett, L. Zhang, R. Birkmire, Laser-fired contact for n-type crystalline si solar cells, Progress in Photovoltaics: Research and Applications 23 (9) (2015) 1091-1099.

10] P. Ortega, G. López, D. Muñoz, I. Martín, C. Voz, C. Molpeceres, R. Alcubilla, Fully low temperature interdigitated backcontacted c-si (n) solar cells based on laser-doping from dielectric stacks, Solar Energy Materials and Solar Cells 169 (2017) 107112 .

11] M. Weizman, H. Rhein, K. Bhatti, R. Duman, C. Schultz, M. Schüle, O. Gabriel, S. Ring, S. Kirner, C. Klimm, et al., Rear-side all-by-laser point-contact scheme for liquid-phasecrystallized silicon on glass solar cells, Solar Energy Materials and Solar Cells 137 (2015) 280-286.

[12] T. Frijnts, S. Gall, H. Rhein, P. Sonntag, L. Mazzarella, S. Kirner, C. Matarazzo, B. Rech, R. Schlatmann, Backside contacted solar cells with heterojunction emitters and laser fired absorber contacts for crystalline silicon on glass, in: 2016 IEEE 43rd Photovoltaic Specialists Conference (PVSC), IEEE, 2016, pp. 2425-2429.

[13] J. Haschke, D. Amkreutz, L. Korte, F. Ruske, B. Rech, Towards wafer quality crystalline silicon thin-film solar cells on glass, Solar Energy Materials and Solar Cells 128 (2014) 190-197.

[14] N. Preissler, C. T. Trinh, M. Trahms, P. Sonntag, D. Abou-Ras, H. Kirmse, R. Schlatmann, B. Rech, D. Amkreutz, Impact of dielectric layers on liquid-phase crystallized silicon solar cells, IEEE Journal of Photovoltaics 8 (1) (2018) 30-37.

[15] U. Jäger, A. Wolf, B. Steinhauser, J. Benick, J. Nekarda, R. Preu, Laser doping for high-efficiency silicon solar cells, in: Laser Material Processing for Solar Energy, Vol. 8473, International Society for Optics and Photonics, 2012, p. 847309.

16] D. Pysch, A. Mette, S. W. Glunz, A review and comparison of different methods to determine the series resistance of solar cells, Solar Energy Materials and Solar Cells 91 (18) (2007) 1698-1706.

[17] S. S. Hegedus, W. N. Shafarman, Thin-film solar cells: device measurements and analysis, Progress in Photovoltaics: Research and Applications 12 (2-3) (2004) 155-176.

[18] J. Haschke, D. Amkreutz, T. Frijnts, S. Kühnapfel, T. Hänel, B. Rech, Influence of barrier and doping type on the open-circuit voltage of liquid phase-crystallized silicon thin-film solar cells on glass, IEEE Journal of Photovoltaics 5 (4) (2015) 1001-1005.

[19] C. T. Trinh, R. Schlatmann, B. Rech, D. Amkreutz, Progress in and potential of liquid phase crystallized silicon solar cells, Solar energy 175 (2018) 75-83.

[20] Y. Yang, G. Xu, K. Zhang, X. Zhang, H. Shen, P. P. Altermatt, P. Verlinden, Z. Feng, Analysis of series resistance of industrial crystalline silicon solar cells by numerical simulation and analytical modelling, 28th EUPVSEC (2013) 1558-1561.

[21] K. Affolter, W. Lüthy, M. Von Allmen, Properties of laserassisted doping in silicon, Applied Physics Letters 33 (2) (1978)
$185-187$.

[22] N. Baber, H. Grimmeiss, M. Kleverman, P. Omling, M. Z. Iqbal, Characterization of silver-related deep levels in silicon, Journal of applied physics 62 (7) (1987) 2853-2857.

[23] F. L. Thiel, S. K. Ghandhi, Electronic properties of silicon doped with silver, Journal of Applied Physics 41 (1) (1970) 254-263.

[24] J. Chen, A. Milnes, Energy levels in silicon, Annual review of materials science 10 (1) (1980) 157-228.

\section{Appendix}

The areas used for resistance calculations are listed below. $A_{\text {cell }}$ is the cell area. $A_{\text {ec_90 }}$ and $A_{\text {ec_60 }}$ are areas of the electron contact with 8 fingers, each $90 \mu \mathrm{m}$ or $60 \mu \mathrm{m}$ wide respectively. Busbars are $1 \mathrm{~cm}$ long and $0.1 \mathrm{~cm}$ wide. Finally, $\mathrm{A}_{\text {fired }}$ is the total area of fired spots on a cell, with 83 spots on each of the 8 fingers. The diameter of the spot fired by the nanosecond laser was used $(33 \mu \mathrm{m})$ as it was responsible for most of the contact resistance improvement (Fig 5).

$$
\begin{array}{r}
A_{\text {cell }}=0.6 * 1=0.6 \mathrm{~cm}^{2} \\
A_{\text {electron contact_90 }}=0.5 * 0.009 * 8+0.1 * 1=0.136 \mathrm{~cm}^{2} \\
A_{\text {electron contact_60 }}=0.5 * 0.006 * 8+0.1 * 1=0.124 \mathrm{~cm}^{2} \\
A_{\text {fired }}=83 * 8 * \pi * \frac{0.0033^{2}}{4}=0.0057 \mathrm{~cm}^{2}
\end{array}
$$

\begin{tabular}{cccc}
\hline $\begin{array}{c}\text { Bulk doping } \\
\text { and electron } \\
\text { contact width }\end{array}$ & $\begin{array}{c}\text { Electron } \\
\text { contact type }\end{array}$ & $\begin{array}{c}\text { Maximum specific } \\
\text { contact resistance } \\
\text { before } \\
\text { laser firing }\end{array}$ & $\begin{array}{c}\text { Maximum specific } \\
\text { contact resistance } \\
\text { after } \\
\text { laser firing }\end{array}$ \\
\hline $\mathrm{cm}^{-3} ;$ m & & $\mathrm{cm}^{2}$ & $\Omega \mathrm{cm}^{2}$ \\
\hline $2.4 \pm 0.5 * 10^{16} ; 120$ & a-Si:H(i/n+)/ITO/Ag & 0.80 & 0.31 \\
$2.4 \pm 0.8 * 10^{16} ; 120$ & a-Si:H(i/n+)/ITO/Ag & 1.40 & 0.77 \\
$2.4 \pm 0.8 * 10^{16} ; 120$ & a-Si:H(i/n+)/ITO/Ag & 1.30 & 0.55 \\
$2.5 \pm 0.5 * 10^{16} ; 120$ & a-Si:H(i/n+)/ITO/Ag & 1.10 & 0.31 \\
$2.5 \pm 0.5 * 10^{16} ; 120$ & a-Si:H(i/n+)/ITO/Ag & 1.60 & 0.50 \\
$2.8 \pm 4.5 * 10^{16} ; 120$ & a-Si:H(i/n+)/ITO/Ag & 1.00 & 0.32 \\
$2.8 \pm 4.5 * 10^{16} ; 120$ & a-Si:H(i/n+)/ITO/Ag & 0.90 & 0.22 \\
$2.4 \pm 0.5 * 10^{16} ; 90$ & a-Si:H(i/n+)/ITO/Ag & 1.10 & 0.36 \\
$2.8 \pm 4.5 * 10^{16} ; 90$ & a-Si:H(i/n+)/ITO/Ag & 1.10 & 0.52 \\
$2.5 \pm 0.5 * 10^{16} ; 90$ & a-Si:H(i/n+)/ITO/Ag & 1.40 & 0.67 \\
$2.5 \pm 0.5 * 10^{16} ; 90$ & a-Si:H(i/n+)/ITO/Ag & 1.10 & 0.53 \\
$2.3 \pm 0.9 * 10^{16} ; 120$ & a-Si:H(n+)/ITO $/ \mathrm{Ag}$ & 0.44 & 0.45 \\
$2.3 \pm 0.9 * 10^{16} ; 120$ & a-Si:H(n+)/ITO/Ag & 0.31 & 0.31 \\
$2.3 \pm 0.9 * 10^{16} ; 120$ & a-Si:H(n+)/ITO/Ag & 0.33 & 0.23 \\
$2.3 \pm 0.9 * 10^{16} ; 120$ & a-Si:H(n+)/ITO/Ag & 0.23 & 0.23 \\
$7.7 \pm 2.7 * 10^{16} ; 120$ & a-Si:H(n+)/ITO/Ag & 0.26 & 0.27 \\
$7.7 \pm 2.7 * 10^{16} ; 120$ & a-Si:H(n+)/ITO/Ag & 0.16 & 0.24 \\
$7.7 \pm 2.7 * 10^{16} ; 120$ & a-Si:H(n+)/ITO/Ag & 0.37 & 0.27 \\
$7.7 \pm 2.7 * 10^{16} ; 120$ & a-Si:H(n+)/ITO/Ag & 0.17 & 0.17 \\
\hline
\end{tabular}

Table 2: The maximum specific contact resistance of a$\mathrm{Si}: \mathrm{H}(\mathrm{i} / \mathrm{n}+) / \mathrm{ITO} / \mathrm{Ag}$ and a-Si:H(n+)/ITO/Ag (i.e, without a-Si:H(i)) before and after laser firing, as used in the calculations in section 3.4 are listed here. These estimates were made by assuming that all series resistance non-idealities are present at the electron contact and that the other components show ideal behaviour. 


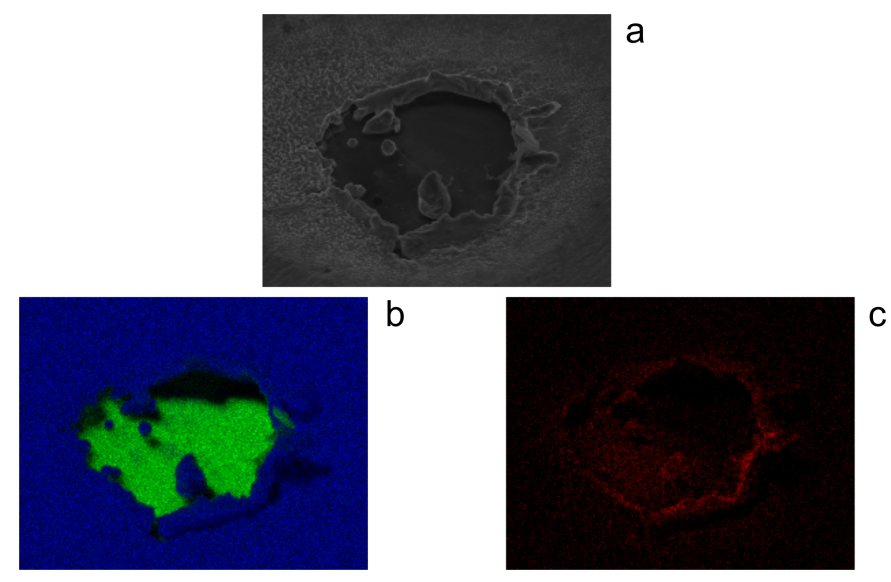

Figure 7: (a) Top view SEM image of a laser fired spot which was analyzed with energy-dispersive X-ray spectroscopy (SEM-EDX). In (b), silver is shown in blue and silicon is shown in green. Only limited over-lap is visible from the top view. (c) shows the presence of oxygen in the laser fired region.
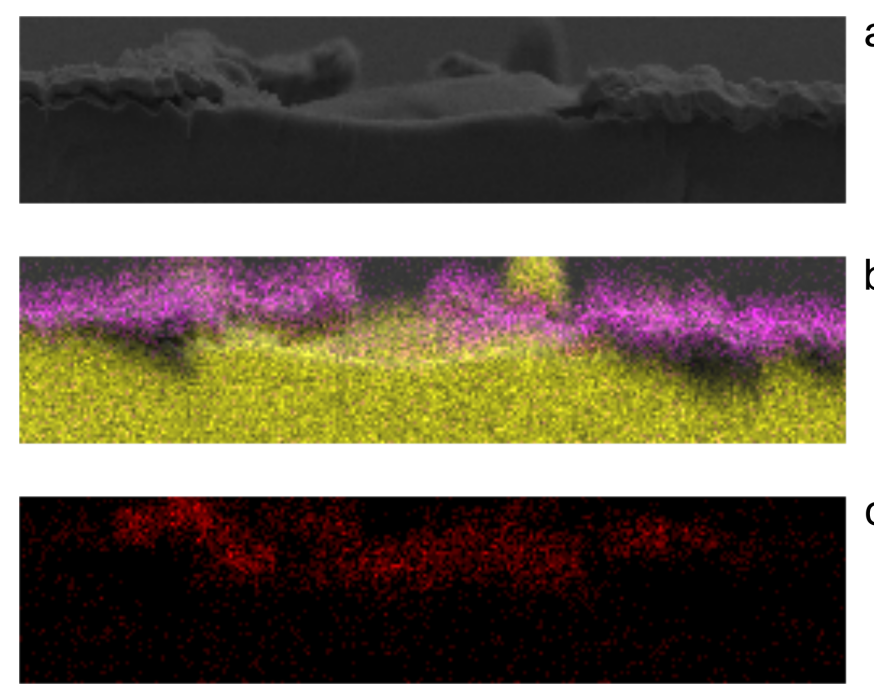

Figure 8: (a) Cross-sectional view SEM image of a laser fired spot which was analyzed with SEM-EDX. In (b), silver is shown in purple and silicon is shown in yellow. Some over-lap is visible in the central region and along the edges of the fired spot. (c) shows the presence of oxygen in the laser fired region. 